\title{
CURRÍCULOS EXCLUDENTES - A CONSTRUÇÃO DE UMA SOCIEDADE LGBTQISFÓBICA
}

\author{
EXCLUDING CURRICULUM - THE BUILDING OF A LGBTQIAPHOBIC SOCIETY
}

\author{
Fábio Pinheiro Ramos de Souza ${ }^{1}$ \\ 1 Universidade do Estado do Rio de Janeiro, Programa de Pós-Graduação em Educação - Processos \\ Formativos e Desigualdades Sociais, Brasil, e-mail: pinheirof54@gmail.com, ORCID: \\ https://orcid.org/0000-0002-0209-0738
}

\begin{abstract}
A R T I CLEINFO
Article history:

Received 2020-05-31

Accepted 2020-11-30

Available online 2020-11-30

Palavras-chave: Currículo. Exclusão. LGBTQIS.

Sociedade

Keywords: Curriculum. Exclusion. LGBTQIA. Society.

RESUMO. Os currículos enquanto base das relações de ensino-aprendizagem estruturam-se em diretrizes de formação laboral e moral. As novas demandas das minorias sociais, crescente no último século, mostram-se acuadas dentro de uma tradição escolar planejada para o controle dos corpos e dos saberes. A formação está a cargo de um currículo pensado para a exclusão e dominação das práticas, não havendo, de forma estrutural, um pensamento inclusivo. As normatividades, desse modo, integram os ciclos de políticas dos currículos, e dentro delas, lançam como artifícios as violências simbólicas para a coerção e invisibilidade da população LGBTQIS. Pedagogias pensadas para a opressão fazem-se presentes nessa dialética entre (re)produção de preconceitos e normatização de condutas. A escola, desse modo, constrói um currículo excludente que contribui para os processos de construção de uma sociedade LGBTQISfóbica. Em uma análise do currículo escolar, articulada com as experiências divulgadas por Junqueira (2009), este artigo busca entender as dinâmicas vividas pela formação dos corpos, conceitos, preceitos e normalidades da escola brasileira.
\end{abstract}

\begin{abstract}
The school curriculum as basis of teaching-learning relationships are structured as guidelines for job and moral training. The new demands of social minorities have grown up in the last century and are shown to be under a school tradition planned for the control of bodies and knowledge. The education is in charge of a curriculum designed to exclude and dominate behaviors, with no inclusive thinking in a structural way. The normatives, therefore, are part of the educational policy cycles of the school curriculum. This normatives launch symbolic violence as coercion and invisibility of the LGBTQIA population. Opressive pedagogies are present in this dialectic between (re) production of prejudices and standardization of conduct. In this way the school builds an excluding curriculum which contributes to build a LGBTQIAphobic society. Due a school curriculum analysis, articulated with the experiences reported by Junqueira (2009), this paper aims to understand the dynamics experienced by the development of bodies, concepts, precepts and normalities of the Brazilian school.
\end{abstract}




\section{Introdução}

A escola atual, derivada de uma construção histórica de interesse burguês, nasce com o propósito de construir uma sociedade ideal, como afirma Michel Foucault (1997). As propostas pedagógicas adotadas por essa escola tradicional alinharam-se aos interesses de classe que reconfiguraram as relações pessoais - e não somente - das sociedades industriais do século XVIII. Desse modo, a escola ganha uma importante função, que é criar uma nova sociedade para antigos pensamentos. Nesse processo, o currículo escolar tem primordial função, sendo ele, o norteador das pedagogias escolares. Além disso, possui uma importância crucial para as diretrizes educacionais, sendo ele parte delas. O currículo é, nesse entendimento, a própria escola. As pedagogias dentro de um espaço escolar, sejam elas intencionais ou espontâneas, estão intrínsecas no currículo praticado.

Assim, compreendê-lo é de fundamental importância já que as pedagogias de repressão - pedagogia do armário e pedagogia do insulto - também perpassam pelo mesmo. A escola é vista como instrumento de controle dos corpos por Foucault e, de forma analítica, enquanto campo para Bourdieu. Este artigo, portanto, destrincha as relações entre a produção e reprodução de uma sociedade LGBTQISfóbica. Desse modo, entender os mecanismos dos currículos excludentes é de grande importância para que possamos combater a evasão escolar, o bullying e promover o respeito à diversidade sexual e de gênero, provenientes do mesmo.

As articulações dos campos políticos brasileiros enxergam na escola a possibilidade de articular a sociedade. Essas novas disputas entram em cena não de forma indireta, mas de forma agressivamente direta como é destrinchado no desenvolvimento a seguir. $O$ currículo escolar brasileiro apresenta-se em nossa contemporaneidade, assim como em sua formação da educação nacional, uma arma de disputa entre campos tradicionais e progressistas.

Portanto, temos como formador dessas práticas, as relações interpessoais e estruturais dos currículos e das políticas que os constroem. Entender os ciclos de políticas, por exemplo, é de extrema importância para compreender as disputas que estão atreladas à formação dos currículos e às transformações entre a sua proposta, formação e, por fim, aplicação. As dinâmicas estão atreladas aos currículos praticados dentro das escolas que, por sua formação histórica, servem a um conservadorismo social. Este artigo tem como objetivo entender as dinâmicas formadoras das relações de produção/ reprodução de LGBTQISfóbias a partir dos currículos escolares. 


\title{
2. Metodologia
}

Para a realização deste artigo foi utilizado a revisão bibliográfica, analisando as relações do currículo frente às aplicabilidades sobre os conceitos abordados a partir de uma coleta de dados em sites jornalísticos, relatórios da área educacional e relatos provenientes de pesquisas de campo. A articulação dos objetos estudados através dos conceitos foi estabelecida dentro de uma análise de documentos e pesquisas na área de currículo escolar.

\section{Desenvolvimento}

Os desafios de um sistema educacional que promova a inclusão entre as diversidades sociais fazem-se necessários com as novas questões identitárias. O surgimento de movimentos sociais politizados no final do século XX consolidam-se no início do século XXI, cobrando novas políticas que supram as necessidades plurais das sociedades pós-modernas. O movimento LGBT ${ }^{1}$ que desde os anos de 1980 vêm através de marchas, petições públicas e organizações civis, conquistando direitos que antes eram negados. A escola, entendida em suas diversas versões, foi eleita pela sociedade como a responsável pela transmissão e validação dos conhecimentos que devem ser transmitidos. Foucault (1997) explica que a formação do cidadão, dessa forma, está ligada diretamente a um projeto de educação - um projeto de escola - em que valores são transmitidos e cultivados. Os saberes desenvolvidos nesses processos pedagógicos em sala de aula e/ou em seu espaço escolar fazem parte do que se intitula currículo. Ele será o responsável pelas diretrizes que irão compor as práticas pedagógicas, os saberes e competências dentro do âmbito escolar. Sendo entendido como

\begin{abstract}
A noção de "currículo em ação", que remete à pluralidade de situações formais ou informais de aprendizagem, geralmente sob a responsabilidade da escola, vivenciadas por estudantes (e também docentes, dirigentes e funcionários/as), que podem ou não ser planejadas e, ainda, ocorrer dentro ou fora da sala de aula. É aquilo que ocorre de fato nas situações vividas pelas escolas, e não o que era desejável e/ou institucionalmente prescrito. (GERALDI, 1994, p.117)
\end{abstract}

O currículo, nesse caso, é o marco central das políticas aplicadas nos espaços educativos. Assim, o norte da escola, para integração ou segregação de práticas, culturas e identidades perpassam pelo mesmo. As relações vividas pelas populações LGBTQIS ${ }^{2}$ de preconceito e bullying nas escolas, são muitas vezes, reflexos das relações de preconceito da sociedade. Logo, os grupos sociais que ocupam as posições centrais, "normais" (de gênero, de sexualidade, de raça, de classe, de religião, etc.) têm possibilidade não apenas de

\footnotetext{
${ }^{1}$ LGBT - Sigla genérica para o movimento de lésbicas, gays, bissexuais e pessoas trans até a primeira década do século XXI.

${ }^{2}$ Sigla proposta por parte do movimento para a integração de novas pautas identitárias; Lésbicas, Gays, Bissexuais, Trans, Travestis, Queers, Intersexuais e Simpatizantes.
} 
representar a si mesmos, mas também de representar os outros, utilizando o currículo para o mesmo (LOURO, 1999). Em um processo cíclico de uma formação LGBTQISfóbica da sociedade, e uma escola reprodutora dos costumes da mesma, chegamos a uma problemática: Como o currículo tem responsabilidade pelas práticas LGBTQISfóbicas na escola? Entender esses processos atrelados à construção do currículo escolar está dentro de disputas por diversos outros setores da sociedade.

A abordagem sobre a marginalização de LGBTQIS necessita ser reconfigurada para a base do problema. A escola, direito do cidadão, formadora dos princípios morais e responsável pela entrega da mão-de-obra para o mercado de trabalho está falhando. Dados da $\mathrm{ABGLT}^{3}$ do ano de 2015 mostram que 73\% dos LGBTs entrevistados entre 13 e 21 anos já sofreram algum tipo de discriminação na escola. A pesquisa realizada pela $A B G L T$, uma rede que reúne 308 organizações pelo país evidencia o que também é uma realidade fora da escola. O currículo escolar, dessa maneira, não está incluindo a problemática LGBTQIS nos processos e relações escolares. O conceito que muitos teóricos utilizam para esse processo de invisibilidade e/ ou não abordagem de temas e questões no currículo é o de currículo oculto. Nesse entendimento, as relações que não estão dentro do currículo oficial seriam entendidos como parte não integrante do mesmo. Neste artigo será trabalhado o entendimento de que todas as práticas efetivamente realizadas na escola por alunos, professores e funcionários estarão ligados diretamente ao currículo. O currículo oficial é, portanto, o currículo praticado.

Mainardes (2006) diz que os ciclos de políticas baseados nos conceitos de Stephen Ball e Richard Bowe estão permeados em três facetas: a política proposta, a política de fato e a política em uso. À vista disso, o ciclo de políticas norteia os currículos escolares em suas propostas que, em muitos casos, são formados de forma verticalizada. Temos, no entanto, a aplicabilidade e a execução dessas políticas que nem sempre são cumpridas ou feitas da forma original. A não ortodoxia das políticas propostas que articulam os currículos apresentam-se para LGBTQIS de duas maneiras. Por um lado, a invisibilidade proposta de forma verticalizada das políticas propostas pode ser reconfigurada pela aplicabilidade no espaço escolar. Por outro, as políticas de uso podem representar, por sua variabilidade, um perigo, principalmente quando as políticas de fato - as legislações e textos políticos - não possuem abrangência direta ao grupo em questão.

Vetada no ano de 2017, parte do texto da BNCC (Base Nacional Comum Curricular) que conferia a obrigatoriedade do ensino sobre respeito à diversidade e orientação sexual é um exemplo de tal importância. Ficam evidentes as disputas anteriormente citadas na criação

\footnotetext{
${ }^{3}$ Associação Brasileira de Lésbicas, Gays, Bissexuais, Travestis, Transexuais e Intersexos (ABGLT) é uma organização brasileira fundada em 31 de janeiro de 1995 com o objetivo e a missão de "promover ações que garantam a cidadania e os direitos humanos de LGBTs".
} 
da BNCC quando a comparamos com outra diretriz curricular da educação brasileira, os PCNs. Os Parâmetros Curriculares Nacionais, diferentes da BNCC não são obrigatórios, mas como o nome sugere, é um parâmetro para guiar os currículos em âmbito nacional. Os PCNs criados em 1997, frente ao veto anteriormente citado de 2017 na BNCC, apresentam uma diferença muito peculiar em suas estruturas de orientação; o tema orientação sexual e sexualidade. Assim, o que temos é a instituição escolar mostrando-se cruamente como uma instituição disciplinar (FOUCAULT, 1997).

A antiga orientação do MEC (Ministério da Educação e Cultura) - hoje como ME (Ministério da Educação) - possuía o tema como proposta transversal para ser trabalhado dentro das disciplinas escolares. A mudança dentro dos 20 anos que se passaram pode ser apontada como uma regressão para o debate e integração das diferentes orientações sexuais que pleiteiam maior participação na sociedade. Essa nova política que acirra o campo da educação brasileira aparenta ser a ponta de um iceberg muito maior. As discussões (falseadas) sobre a ideologização das escolas para um aparelhamento ganhou força na última década, acirrando ainda mais os discursos - e os currículos - futuros da educação brasileira.

O movimento do "Escola sem Partido" criado em 2003 pelo advogado Miguel Nagib4, dentro de uma lógica de tradicionalismo educacional, propõe que os currículos escolares não abordem posicionamentos políticos. Essa ideia de "neutralidade" curricular funciona como um sistema para perpetuar o que já é consagrado como recorrente. As discussões trazidas pelo advogado rapidamente ganharam adeptos no congresso, obtendo da bancada religiosa os apoios mais fiéis. O grupo endossou nas suas demandas a agenda do movimento, criando uma proposta agressiva de currículo excludente. O projeto de lei 867 de 2015 exemplifica em sua composição:

Art. 3ํㅗ̃o vedadas, em sala de aula, a prática de doutrinação política e ideológica bem como a veiculação de conteúdos e a realização de atividades que possam estar em conflito com as convicções religiosas ou morais dos pais ou responsáveis pelos estudantes. (PROJETO DE LEI № 867, 2015)

Os embates entre os setores ganham espacialidades nas escolas e o resultado pode ser visto no trabalho desenvolvido por Junqueira (2009), em que analisa as relações do currículo e as práticas homofóbicas na escola pública brasileira. Desse modo, trabalha com relatos e conceitos como o da pedagogia do armário, nos quais deixam claro como as heteronormatividades do currículo excluem aqueles que não estão dentro do padrão pensado

\footnotetext{
${ }^{4}$ É procurador do Estado de São Paulo em Brasília desde 1985 e foi assessor de ministro do Supremo Tribunal Federal de 1994 a 2002
} 
para ele. Em um de seus relatos abordou a seguinte situação exposta por um professor de Educação Física:

\begin{abstract}
"Os meus alunos protestaram contra a permanência de um colega gay no time de futebol. Disseram: "Veado é a pior coisa que existe!" Temos um problema em minha escola: um garoto afeminado demais, com muitos trejeitos. Ele apanha sempre dos colegas, e todos os professores riem dele. Já lhe disse: "Tu és gay, eu respeito, mas pára de desmunhecar, pois estás atraindo a ira dos outros sobre ti." Mandei chamar a mãe dele. Ele está com 6 anos agora. [...] Que fiz com os outros? Fazer o quê?"
\end{abstract}

No discurso do professor de Educação Física temos a exemplificação do conceito abordado sobre a pedagogia do armário. Ela, quando integra o currículo escolar, faz das relações de gênero e sexualidade desviantes do padrão heterossexual e/ou cisgênero ${ }^{5}$, uma diferença que deve ser combatida - e em explícita relação ao armário - guardada. No mesmo diálogo, o problema abordado pelo professor não é a discriminação e homofobia, e sim, a própria existência - e diferença - do aluno. O controle das condutas tidas como transgressoras do que se entende como corretas pela sociedade é apontado por Foucault como semelhantes em suas várias esferas de dominação. Para que

[...] a vigilância seja permanente em seus efeitos, mesmo se é descontínua em sua ação; que a perfeição do poder tenda a tornar inútil a atualidade de seu exercício; que esse aparelho arquitetural seja uma máquina de criar e sustentar uma relação de poder independente daquele que o exerce; enfim, que os 11 detentos se encontrem presos numa situação de poder que eles mesmos são os portadores. (FOUCAULT, 1997, p. 224-225)

Outro conceito importante abordado pelo autor é o da pedagogia do insulto, em que há mescla de práticas, classificações, relações de poder, atitudes excludentes, elaborações de conhecimentos e saberes presentes no cotidiano escolar que atuam por meio dos sujeitos e das diferenças que o currículo constrói, divulga e defende sob o comando de normas de gênero e da heteronormatividade (BARREIROS, 2017). Segundo o autor, entende-se que as práticas de discriminação por alunos, professores e pelo próprio currículo pensado estão diretamente ligados a um processo de ensinamento da conduta para com o próximo. Em uma das declarações dos professores entrevistados, temos o seguinte relato:

"Numa festa, um menino de 5 anos ficou com o último balão. Não queria porque era cor-de-rosa. A quem passava ele dizia: "Olha, eu não escolhi esse balão". Temia

\footnotetext{
5 cisgênero é a pessoa cuja identidade de gênero corresponde ao gênero que lhe foi atribuído no nascimento.
} 
que o pai viesse buscá-lo. Depois, a coordenadora disse para não fazermos mais balões rosas nas festas em que há meninos. O vice-diretor sempre se refere a um determinado aluno como "aquela coisa".

Nesse relato trazido por Junqueira (2009), temos a exemplificação do conceito da pedagogia do insulto, que pode ser definida como práticas rotineiras em que, com o discurso verbal e não verbal, o aluno seria "educado", através de violências, a não cometer práticas, hábitos e condutas tidas como não normativas. Os conceitos, anteriormente apresentados nesse artigo, estão relacionados a um outro conceito trabalhado por Bourdieu, a violência simbólica. Nesse contexto, o currículo pode ser utilizado por toda a sua potência enquanto norteador das práticas escolares, como um instrumento para produzir - e reproduzir - uma sociedade homofóbica/ transfóbica. Segundo Bourdieu (2002), para que a dominação simbólica funcione é necessário que os dominados tenham incorporado às estruturas segundo as quais os dominantes os apreendem; que a submissão não seja um ato de consciência susceptível de ser compreendido na lógica do constrangimento ou na lógica do conhecimento. Bourdieu (2002) e Foucault (1997) afirmam que a violência não precisa ser física, marcada no corpo, mas não deixa de ser uma violência psicológica, em que o próprio indivíduo com receio de ser punido ou excluído, se auto vigie constantemente.

Assim, os currículos em suas amplas aplicações e possuidores de múltiplas moradas, quando incorporadas em escolas que não se fazem singulares, estão sendo postos como afirma César (2010), em seu pensamento foucaultiano, que o "sexo bem educado" fez (faz) parte da formação escolar. Assim, entende-se que

A lei não é internalizada literalmente, mas incorporada, com a conseqüência de que se produzem corpos que expressam essa lei no corpo e por meio dele; a lei se manifesta como essência do eu deles, significado de suas almas, sua consciência, a lei de seu desejo. Com efeito, a lei é a um só tempo plenamente manifesta e plenamente latente, pois nunca aparece como externa aos corpos que sujeita e subjetiva. (BUTLER, 2003, p.193).

Diante disso, os currículos escolares estão atrelados à formação que ultrapassa a ideia de construção do conhecimento objetivo e laboral. As práticas aprendidas e reproduzidas na escola - e orientadas pelos currículos - fazem parte de um sistema mais amplo de sociedade que o prioriza em disputas na busca do domínio dos saberes e práticas sociais.

Para entendermos de forma mais efetiva a relação entre currículo e seus impactos na construção de uma sociedade, Bourdieu (1992) apresenta o conceito de habitus. Ele se organiza pelo entendimento de que as práticas sociais e a construção do indivíduo ocorrem através dos valores e das corporalidades. Assim, a construção do ser humano perpassa pela interação do ethos e hexis. O ethos estaria ligado aos princípios, valores e moral do cotidiano em que constituem o indivíduo durante a sua formação, o hexis às corporalidades, posturas e relações com o corpo em que o indivíduo foi submetido ao campo durante a sua construção 
social. Esses dois conceitos, somados ao habitus, expõem as dificuldades da aceitação e respeito às diferenças de performidade de gênero ${ }^{6}$ e sexualidade. A construção de uma não "normalidade" LGBTQIS, dentro dos conceitos apresentados, se fazem de forma estruturante, o que dificulta a normalização dos ethos e hexis diferentes. É importante ressaltar que as condições de reprodução não eximem as diferenças que possam existir entre as minorias anteriormente citadas, que possuem origens sociais diferentes, perpassando pelas categorias de classe e raça. Assim, o conceito de campo é determinante para os processos de maior ou menor discriminação, já que na sociedade capitalista, a classe - e as construções histórico sociais de raça - são pontos importantes nas relações de exclusão, mesmo em minorias da mesma categoria. Para que haja uma mudança dos conceitos de normalidade dos comportamentos e da moral, uma mudança do campo, ou seja, da escola, poderia ser potencial.

A escola, eleita pela sociedade como instituição apta para fazer a transmissão dos conhecimentos e moralidades tida como válidos pela sociedade, é na realidade, junto das estruturas que formam a sociedade, um instrumento de dominação e controle dos ethos e hexis, pondo os mesmos como barreira para a mudança social. Com o controle das ações e dos preceitos das elites econômicas e morais, o controle dos corpos, seus comportamentos e conhecimentos são mais uma vez uma barreira para alunos não enquadrados nas estruturas sociais dominantes. Dessa forma, o capital cultural também passa a ser uma barreira para as vivências escolares. A evasão, em muitos casos, ocorre pelo não enquadramento dos ethos e hexis e do capital cultural adquiridos durante o processo de formação do habitus, integrantes do currículo. A estrutura das pedagogias do armário e do insulto são mecanismos de controle dos corpos, nesse processo de preparo social. Mészáros (2005) em sua análise sobre a educação brasileira afirma que

A educação institucionalizada, especialmente nos últimos 150 anos, serviu - no seu todo - ao propósito de não só fornecer os conhecimentos e o pessoal necessário à máquina produtiva em expansão do sistema do capital, como também gerar e transmitir um quadro de valores que legitima os interesses dominantes [...]. (MÉSZÁROS, 2005, p. 35)

Logo, a dominação através do processo da reprodução das culturas, normas e práticas dominantes são disseminadas dentro da estrutura escolar. Pessoas trans, gays, lésbicas, bissexuais e/ou que possuam algum comportamento não normativo de gênero ou de

\footnotetext{
${ }^{6}$ Performidade de gênero - O gênero é entendido como uma construção social, e por isso, o gênero pode ser atribuído ao indivíduo sem que haja uma relação biológica pré-definida.
} 
sexualidade, por transgredirem as normas estabelecidas por tais culturas, estão a todo momento passando por violências simbólicas - e não somente - para que haja um enquadramento e uma efetiva reprodução. Esse reforço do habitus, através das pedagogias, é entendido pelo autor como um processo que

[...] produz o desconhecimento das limitações implicadas nesse sistema, de sorte que a eficácia da programação ética e lógica por ele produzida se encontra redobrada pelo desconhecimento das limitações inerentes a essa programação. A ação pedagógica tende a produzir o reconhecimento da legitimidade da cultura dominante, tende a lhes impor do mesmo modo, pela inculcação ou exclusão, o reconhecimento da ilegitimidade de seu arbitrário cultural. (BOURDIEU; PASSERON, 1992, p. 52-53)

Assim, há uma formatação dentro da escola, lugar que foi construído para não servir a diversidade e para ser um espaço de legitimação de uma classe. Dessa maneira, a escola enquanto campo funciona como um sistema de filtro cultural e social.

\section{Considerações finais}

As disputas que envolvem a escola, e com ela o próprio currículo, evidenciam como a composição do mesmo é de extrema importância para a formação de uma sociedade. Não há escola sem currículo, ou currículo sem escola, já que as potencialidades dos currículos são produtoras e norteadoras de pedagogias, sejam elas inclusivas ou não.

A escola como formadora do cidadão ideal é, em conjunto, a responsável pelas reproduções e também pelas rupturas de valores que são entendidos por uma sociedade. Portanto, cabe a educação - e nela em seu contexto geral - construir em comum pluralidade os valores e conhecimentos válidos para um país. A proposta social integradora de uma formação curricular tem como resultado a produção de uma sociedade também integradora.

Trazendo as contribuições de Foucault (1997) para o entendimento da estrutura escolar - e por isso curricular - pode-se entender que a mesma serve a valores dominantes e que possui um propósito maior. A formação de um currículo que alinha a sociedade a um interesse dominante é a representação do projeto de escola conservadora que se desenhou - e se desenha - no Brasil. Os embates que produzem currículos cada vez mais limitantes impactam na formação social, tendo assim, a produção de currículos excludentes, e como consequência, a formação de uma sociedade LGBTQISfóbica. 


\section{REFERÊNCIAS}

BARREIROS, Douglas Paulino. Pedagogia do insulto: A exclusão atuando no currículo escolar. Revista educação, São Paulo, 2017.

BOURDIEU, Pierre; PASSERON, Jean-Claude. A reprodução. 3.ed. Rio de Janeiro: Francisco Alves, 1992.

BOURDIEU, Pierre. A produção da crença: contribuição para uma economia dos bens simbólicos. São Paulo: Zouk, 2002.

BRASIL. MEC. Base Nacional Comum Curricular. Brasília: MEC, 2017. Acesso em: 23 agosto 2019.

BUTLER, Judith. Problemas de gênero. Rio de Janeiro: Civilização Brasileira, 2003.

CÉSAR, Maria Rita de Assis. Gênero, sexualidade e educação: notas para uma “Epistemologia”, Educar, Curitiba, n. 35, p. 37-51. Editora UFPR, 2009.

FOUCAULT, Michel. Vigiar e punir. 21. ed. Petrópolis: Vozes, 1997.

GERALDI, Corinta Maria Grisolia. Currículo em ação: buscando a compreensão do cotidiano da escola básica. Proposições, Campinas, v. 5, n. 3 [15], nov, 1994.

JUNQUEIRA, Rogério Diniz. (Org.). Diversidade sexual na educação. Brasília: MEC, 2009.

LOURO, Guacira Lopes. (Org.). O corpo educado. Belo Horizonte: Autêntica, 1999.

MAINARDES, Jefferson. Abordagem do ciclo de políticas: uma contribuição para a análise de políticas educacionais. Educação e Sociedade, Campinas, v. 27, n. 94, p. 47-69, jan./abr. 2006.

MÉSZÁROS, István. A Educação para além do capital. São Paulo: Boitempo Editorial, 2005.

Miguel Nagib. Câmara Legislativa, 2015. Disponível em: $<$ https://www2.camara.leg.br/atividade-legislativa/comissoes/comissoes-

permanentes/ce/audiencias-publicas-1/apresentacoes/apresentacao-miguel-nagib>. Acesso em: 29, maio de 2020 